\title{
Point Prevalence Study of Communicable and Non-Communicable Diseases and Cervical Cancer Screening in Female Sex Workers (FSW) in an Urban Area of Eastern India
}

\author{
Puja Chatterjee ${ }^{1 *}\left(\mathbb{D}\right.$, Rupali Dey ${ }^{2}$ (i) Dipanwita Banerjee ${ }^{1}(\mathbb{D})$, Manisha Vernekar ${ }^{1}$ (iD
}

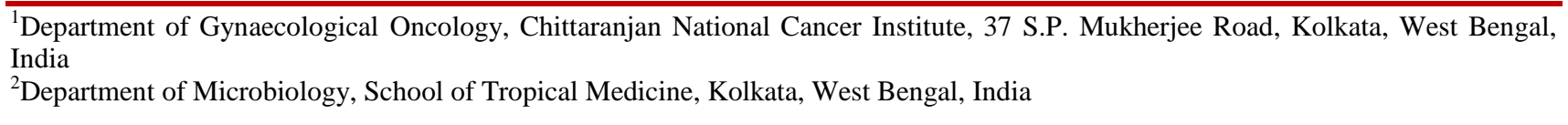

*Corresponding author: Puja Chatterjee

Abstract

Background: Female sex workers (FSW) in India represents a vulnerable population with limited access to health care services. This study aims to determine the point prevalence of communicable and non-communicable diseases along with incidence of cervical precancers. Methodology: After house-to-house sensitization drive, FSW between the age 25-65 years attended a health-camp in a high-risk area. After informed consent, the women underwent general examination including blood pressure, cervical pap smear and routine blood investigations. Women with abnormal smears were recalled for Human papilloma Virus (HPV) screening and colposcopy. Counselling and follow-up checkups were arranged for these women. Treatment was provided for the Sexually transmitted Infections (STI), hypertension, diabetes and anaemia. Results: Out of 66 women, 55\% women were obese while $8 \%$ were underweight. Hypertension was seen in $31 \%$, diabetes in $3 \%$ and anaemia in $84 \%$ women. $26 \%$ women tested positive for syphilis and $3 \%$ tested positive for HIV and Hepatitis B each. Treatment was given for trichomoniasis which was detected in 7 women (13\%). Low-grade Squamous Intraepithelial Lesion (LSIL) was detected in 11(21\%), High-grade Squamous Intraepithelial Lesion (HSIL) in 2(4\%), 39(74\%) were negative for intraepithelial malignancy and $1(1 \%)$ had inconclusive smear. Out of the 13 HSIL and LSIL, 7(54\%) returned for HPV screening and colposcopy. Colposcopy was satisfactory and normal for all. All women were asked to return to the Institute for follow-up as per routine screening guidelines. Conclusion: The incidence of cervical precancer (LSIL and HSIL) was 24.5\% (13/53). FSW need better access to health care including STI screening and cervical cancer screening.

Keywords: Sex workers, Sexually transmitted Diseases, Non-communicable diseases, Hypertension, Diabetes.

Copyright $(\mathcal{C} 2021$ The Author(s): This is an open-access article distributed under the terms of the Creative Commons Attribution 4.0 International License (CC BY-NC 4.0) which permits unrestricted use, distribution, and reproduction in any medium for non-commercial use provided the original author and source are credited.

\section{INTRODUCTION}

Stigma and discrimination against commercial sex workers (CSW) makes it difficult for them to access health services in general. While sex work per se is not a crime in India, soliciting for sex work and living off the wages of a sex worker is criminalised by the Immoral Trafficking Prohibition Act (ITPA), 1956 [1]. The knowledge of government benefit schemes and their utilization remains under question. It is estimated that over 60,000 brothel-based women and girls are involved in prostitution in Kolkata, a city in Eastern India. The exact number is impossible to quantify, as many women often shift from one area to another. Some women may live in a red-light area but go out to work. There are also women who live outside the area but enter during the day to work [1].
Cervical cancer has been classified as an AIDS-defining illness. With increased life expectancy following the introduction of antiretroviral therapy (ART), HIV-positive women are at high risk of precancerous lesions of the cervix and invasive cervical cancer due to immune suppression by HIV infection that appears to worsen the outcome of HPV infection. The prevalence of HIV in the state of West Bengal is $0.20 \%$ [0.14-0.27] [2] with 1.44 lakh people living with HIV in the state. National Integrated Behavioural and Biological Surveillance (IBBS) has estimated HIV prevalence of $2.2 \%$ among Female Sex Workers (FSWs) nationally [3]. 


\section{METHOD}

House to house sensitisation visits were conducted in the residence locality of the FSW with the help of local Non-Government Organisation over a period of seven days to increase their awareness of the reproductive health issues and finally motivating them to attend the health camps. FSW between the age 25-65 years workers were invited to a health screening camp.

Inclusion Criteria: 1. Age 25-65years apparently healthy FSW.

Exclusion Criteria: 1. Women who did not consent to per speculum examination 2. Pregnant 3. Menstruating women 4 . Women who have undergone hysterectomy

After taking informed consent and following principles of Declaration of Helsinki, eligible women underwent general examination including blood pressure and Body Mass Index (BMI). They underwent blood tests for haemoglobin, random blood sugar, VDRL (venereal disease research laboratory test for syphilis), Hepatitis B antigen (HbsAg), Anti-Hepatitis C Antibody (Anti HCV) and Human Immunodeficiency Virus (HIV I \&II). General health concerns were answered. Syndromic management was provided for vaginal discharge. Treatment was provided for anaemia, hypertension, diabetes and asthma.

Per speculum examination followed by cervical pap smear was done in an enclosed private area. Women with abnormal Pap tests were invited to a regional cancer Institute for colposcopy and Human Papilloma Virus (HPV) testing. The findings were recorded in a case record form. Counselling was done for importance of cervical cancer screening and followup visits.

\section{RESULTS}

The camp was attended by 66 women. $13(19.7 \%)$ women were excluded (2 pregnant, 3 less than 25 years, 1 hysterectomy, 4 did not allow, 3 menstruating women). After taking informed consent, 66 women underwent general examination and blood tests. Per speculum examination followed by cervical pap smear was done for 53 women.

\section{Demographic Parameters:}

The mean age was 34 years (Range- 2252 years). Out of these 66 women only $4(6 \%)$ women were post-menopausal. The women were categorized as underweight ( $<18.5 \mathrm{~kg} / \mathrm{m} 2)$, normal BMI (18.5-22.9 $\mathrm{kg} / \mathrm{m} 2)$, overweight $(23.0-24.9 \mathrm{~kg} / \mathrm{m} 2)$ and obese $(\geq 25$ $\mathrm{kg} / \mathrm{m} 2$ ) based on the revised consensus guidelines for India. Obesity was found in $36(55 \%)$ while only $5(8 \%)$ were underweight. Normal BMI was found in $17(26 \%)$ and $8(12 \%)$ were overweight.
Five women $(8 \%)$ did not disclose their reproductive history. On enquiring upon the number of unwanted pregnancies that resulted in termination of pregnancy (TOP), we found that 20/61 (33\%) had one TOP, $7 / 61(11 \%)$ had two TOP and $3 / 61(5 \%)$ had three TOP. Thirty-one women $(51 \%)$ were nulliparous. The women reported diverse general complains out of which the most common complain was that of vaginal discharge which was reported by $13 \%$ women for whom syndromic management was advised (Table-1).

\section{Non-communicable diseases (Table-2)}

Anaemia (haemoglobin or $\mathrm{Hb}$ less than $12 \mathrm{~g} / \mathrm{dl}$ ) was found in 54/66(82\%). 25(38\%) women had moderate to severe anaemia with the lowest haemoglobin of $5.5 \mathrm{~g} / \mathrm{dl}$. Women with severe anaemia requiring immediate attention were referred to a nearby hospital. Hypertension $(\mathrm{BP}>=140 / 90)$ was found in $14 \%$, Diabetes in 3\%, asthma/ chronic obstructive pulmonary disease in $3 \%$ and newly diagnosed hypothyroidism in $5 \%$.

\section{Communicable Diseases}

Trichomoniasis was found on pap smears of 7 women (13\%), all of whom were found to be negative for intraepithelial malignancy (NILM). Tablet Metronidazole $400 \mathrm{mg}$ thrice daily was given to the women in whom symptomatic treatment was not prescribed earlier. VDRL was found to be reactive in 17 women $(26 \%)$ and none of them gave a previous history of diagnosis or treatment of syphilis. None of them had clinical signs of syphilis. Three women $(4.5 \%)$ were found to be HIV positive and two $(3 \%)$ were Hepatitis $B$ positive. None of them were positive for antiHepatitis $\mathrm{C}$ antibody. These women were referred to the nearest government hospital for treatment and followup.

\section{Cervical cancer screening (Table-3)}

No cases of ASCUS, ASCUS-H, invasive squamous cell carcinoma or glandular abnormalities were found. The focus of any cervical cancer screening project lies on the abnormal precancers and not the frankly invasive cases. The incidence of abnormal smears in our study is $13(24.5 \%)$. The woman with inadequate smear did not turn up for repeat pap smear. Out of the 13 women with abnormal smears (HSIL and LSIL), 7(53.8\%) came for further evaluation at the Institute where they underwent HPV testing and colposcopy. Out of these, Colposcopy was adequate and normal (swede score $<5)$ for all of them. One of the HSIL women, tested positive of HR-HPV and underwent biopsy which came out to be normal. All these women have been asked to return for routine after 5 years.

Out of these 13 women with abnormal smears, only $4(30.8 \%)$ had symptoms of vaginal discharge and the rest had no specific complains $(69.2 \%)$. The mean age of these women was 37 years and 2 of them were 
Puja Chatterjee et al., SAS J Surg, Apr, 2021; 7(4): 201-206

post-menopausal. Two (15.4\%) of them tested positive for VDRL, 1(7.7\%) was HbsAg positive while none of them tested positive for HIV. All these women had an apparently normal cervix on speculum examination.

Table-1: Distribution of women with presenting complains

\begin{tabular}{|l|l|l|}
\hline Presenting complains & Number & Percentage \\
\hline No complains & 21 & $32 \%$ \\
\hline Menstrual complains & 7 & $11 \%$ \\
\hline Vaginal discharge & $\mathbf{9}$ & $\mathbf{1 4 \%}$ \\
\hline Pain abdomen & 6 & $9 \%$ \\
\hline Dyspareunia & 2 & $3 \%$ \\
\hline Missing thread of copper t & 2 & $3 \%$ \\
\hline Recurrent Pregnancy loss & 1 & $2 \%$ \\
\hline Skin problems & 1 & $2 \%$ \\
\hline Piles & 3 & $5 \%$ \\
\hline Breast complains & 2 & $3 \%$ \\
\hline Others(like low back pain, acidity, dizziness) & 13 & $20 \%$ \\
\hline Total & 66 & $100 \%$ \\
\hline
\end{tabular}

Table-2: Non communicable systemic Diseases

\begin{tabular}{|c|c|c|}
\hline Non- communicable diseases & Number & Percentage \\
\hline Diabetes & 2 & $3 \%$ \\
\hline Hypertension & 9 & $14 \%$ \\
\hline Grade 1 & 5 & $8 \%$ \\
\hline Grade 2 & 4 & $6 \%$ \\
\hline Grade 3 & 0 & $0 \%$ \\
\hline Asthma & 2 & $3 \%$ \\
\hline Hypothyroidism & 3 & $5 \%$ \\
\hline Anaemia & 54 & $82 \%$ \\
\hline No anaemia $(<12 \mathrm{~g} / \mathrm{dl})$ & 12 & $18 \%$ \\
\hline Mild anaemia $11-11.9 \mathrm{~g} / \mathrm{dl}$ & 29 & $44 \%$ \\
\hline Moderate anaemia $(8-10.9 \mathrm{~g} / \mathrm{dl})$ & 22 & $33 \%$ \\
\hline Severe anaemia $<8 \mathrm{~g} / \mathrm{dl}$ & 3 & $5 \%$ \\
\hline
\end{tabular}

*(As per http://www.apiindia.org/medicine_update_2013/chap17.pdf) Grade 1 hypertension: SBP 140-159 mm Hg\&/or 90-99mm Hg Grade 2: SBP 160-179 mm Hg DBP 100-109 mm Hg Grade 3: SBP- >=180 mm Hg DBP>=110 mm Hg

Table-3: Cervical Papanicolaou smear test results

\begin{tabular}{|l|l|l|}
\hline PAP test results & Number & Percentage \\
\hline LSIL & 11 & $\mathbf{2 1 \%}$ \\
\hline NILM & 39 & $74 \%$ \\
\hline HSIL & 2 & $\mathbf{4 \%}$ \\
\hline Inadequate & 1 & $2 \%$ \\
\hline ASCUS & 0 & $0 \%$ \\
\hline ASCUS-H & 0 & $0 \%$ \\
\hline Invasive & 0 & $0 \%$ \\
\hline Total & 53 & $100 \%$ \\
\hline
\end{tabular}

LSIL- Low-grade Squamous Intraepithelial Neoplasia, HSIL- High-grade Squamous Intraepithelial Neoplasia, NILM= Negative for Intraepithelial Malignancy

Table-4: Comparing results of our study to the NFHS 4 data for the state of West Bengal, India for 2015-2016

\begin{tabular}{|l|l|l|l|l|l|}
\hline & & Our Study (\%) & \multicolumn{2}{l|}{ NFHS 4 (2015-2016) } \\
\hline & Parameters & & Urban(\%) & Rural(\%) & Total(\%) \\
\hline Nutritional status & BMI $<18.5 \mathrm{~kg} / \mathrm{m}^{2}$ & $\mathbf{8}$ & 14.1 & 24.6 & 21.3 \\
\hline & BMI $>25 \mathrm{~kg} / \mathrm{m}^{2}$ & $\mathbf{5 5}$ & 30.6 & 15.0 & 19.9 \\
\hline Anaemia (15-49 years) & Hb<12g/dl non pregnant & $\mathbf{8 0 . 3}$ & 58.4 & 64.8 & 62.8 \\
\hline Diabetes & Blood sugar $>140$ mg/dl (High) & 0 & 8.7 & 6.8 & 7.4 \\
\hline & Blood sugar $>160$ (very high) & 3 & 4.2 & 3.2 & 3.5 \\
\hline Hypertension & Grade 1 & 8 & 9.1 & 7.3 & 7.9 \\
\hline & Grade 2 & 6 & 2.2 & 1.7 & 1.9 \\
\hline & Grade 3 & 0 & 0.8 & 0.7 & 0.7 \\
\hline
\end{tabular}


Table 5: Comparison of our study to another study on female sex workers in Eastern India

\begin{tabular}{|l|l|l|}
\hline & Our Study & Mondal et al \\
\hline Sample size (undergoing pap smear) & 53 & 60 \\
\hline Location & Camp based & Hospital Based \\
\hline Normal & 74 & 13.3 \\
\hline ASCUS & 0 & 3.3 \\
\hline LSIL & 21 & 15 \\
\hline HSIL & 4 & 38.3 \\
\hline AGUS & 0 & 1.7 \\
\hline invasive & 0 & 3.3 \\
\hline
\end{tabular}

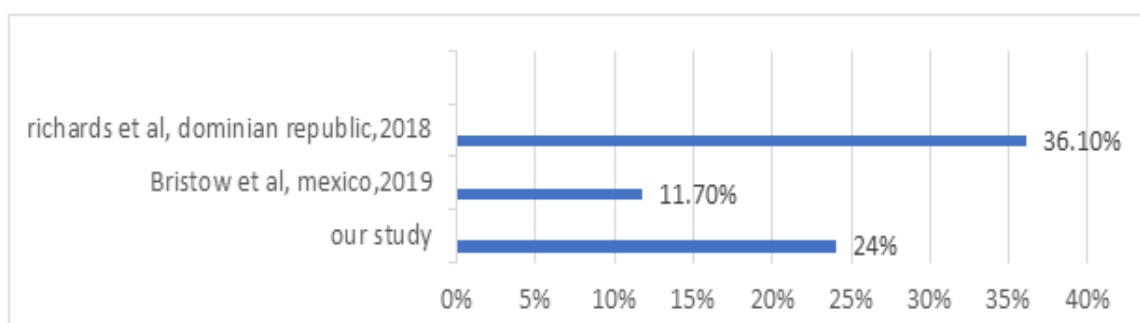

Fig-1: Comparing the prevalence of abnormal smears of our study to other studies done in women CSW

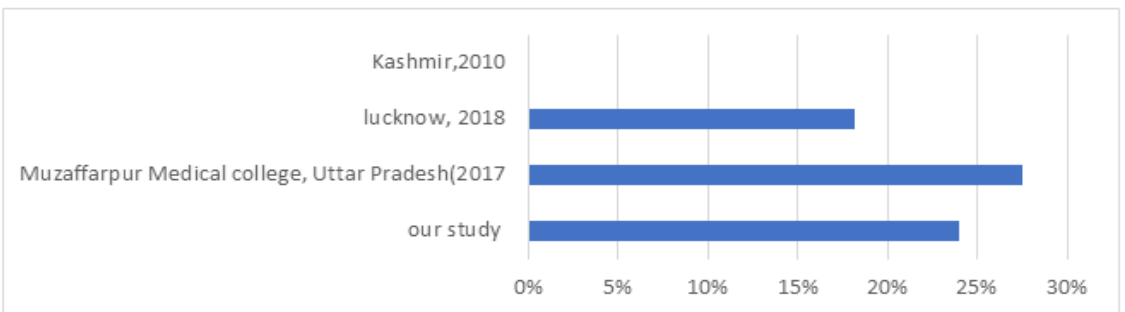

Fig-2: Comparison of the abnormal pap smear results of our study to other studies conducted in India on the general population

\section{DISCUSSION}

Social stigma makes the FSWs unwilling to access health care facilities even when available [4]. Surveys have revealed that the prevailing social attitude of demarcating CSWs as outcasts is highly prevalent among healthcare workers including physicians [5]. A study among CSWs in India have shown that more than two-thirds of them have had a very negative experience in hospitals or rehabilitation centres [6]. Such experiences often deter them from seeking healthcare in future. This trend is, by no means, specific to India. Studies involving CSWs from other countries have also shown that CSWs were often refused treatment by medical personnel just because of their profession. Being HIV positive increased this stigma and negative attitude even further [7].

The women in our study have not undergone any previous cervical cancer screening in the past. As per National Family Health Survey -4 (NFHS-4) 20152016 data $^{8}, 4.6 \%$ urban women and $3.9 \%$ urban women have undergone cervical screening in West Bengal. None of them have been vaccinated by Human Papilloma Virus vaccine. NFHS 4 data tells us that $2.6 \%$ urban women and $2 \%$ rural women have undergone breast cancer screening whereas in the population in our study have never undergone breast cancer screening. The door-to-door campaigning played a very important role as that helped to reduce the inhibitions and apprehensions of these women. These women were used to pro-bono general health camps but however this was the first time somebody talked to them about cervical cancer prevention.

Obesity was found in $55 \%$ of these women and only $8 \%$ women were undernourished. In contrast, anaemia (Haemoglobin $<12 \mathrm{~g} / \mathrm{dl}$ ) was found in $84 \%$. Percentage of women with obesity and anaemia was strikingly different and much higher in proportion to the NFHS 4 data whereas the percentage of women who were undernourished was much less (Table-4) [8]. Malnutrition is an all-inclusive term that represents all manifestations of poor nutrition. It can mean any or all forms of undernutrition, overweight, and obesity [9]. This is usually associated with micronutrient deficiencies which ultimately may lead to anaemia due to iron deficiency. Thus, the importance of promoting a healthy food environment - including food systems that promote a diversified, balanced and healthy diet requires the involvement of multiple sectors and stakeholders, including government, and the public and private sectors. Governments have a central role in creating a healthy food environment that enables people to adopt and maintain healthy dietary practices [10]. 
Puja Chatterjee et al., SAS J Surg, Apr, 2021; 7(4): 201-206

Lack of physical exercise also plays a contributory factor. The percentage of women with diabetes and grade 1 and 3 Hypertension were also found to be similar to the NFHS 4 data. However, grade 2 Hypertension rates were much higher.

The prevalence of HIV in the state of West Bengal is $0.20 \%$ whereas in our population group it is $4.5 \%$ (3/66). The very high VDRL reactive numbers may signify higher STI rates. The average estimated carrier rate of hepatitis B virus (HBV) in India is $4 \%$, with a total pool of approximately 36 million carriers [11]. This was consistent with our study's Hepatitis B antigen positivity rate of $3 \%$. A study from Surat, India showed $43 \%$ prevalence of HIV and $23 \%$ prevalence of Syphilis in female CSWs [12]. The prevalence rate of Syphilis $(26 \%)$ was similar but out HIV positivity rate $(4.5 \%)$ was much lower.

In this study, the prevalence of cervical precancer (LSIL and HSIL) was 24\% (13/53). The prevalence of an abnormal Pap was $11.7 \%$ (35/300) in a study in Mexico [13]. In another study in the dominion republic $36.1 \%$ (52/144) of Pap-smears were abnormal (Figure-1) [14]. The drawback of study was that we did not perform high risk HPV testing for all women. We did this testing only for the women with abnormal smears due to financial constraints.

The single study from 2017 evaluated abnormal smears in female sex-workers in Eastern India (Table-5) [15]. However, their population were selected from patients who were attending outpatient department of a tertiary hospital with different clinical symptoms such as abdominal pain, bleeding per vagina, vaginal discharge, irregular menstruation etc. Our study was camp based and most of the patients were asymptomatic. Possible reasons for the much lower values quoted in our study is that most of the women in our study were asymptomatic while their population had already presented with some or the other symptom. The abnormal pap smear results of our study were compared to other studies conducted in India on the general population. $27.5 \%$ in a study in Uttar Pradesh, $18.2 \%$ in Lucknow and 0 in Kashmir (Figure-2) [16$18]$.

Because of the limited sample size, it is difficult to comment on the risk factors leading to cervical precancers. The other limitation is that pap smear test is not a point of care test with varying sensitivity depending on the pathologist. A visual examination under acetic acid would have led to lower drop-out rates and been financially more viable option in this population.

\section{CONCLUSION}

India has an escalating burden of noncommunicable diseases and needs to divert resources for tackling this global epidemic. Anaemia was the most common noncommunicable disease with point prevalence of $82 \%$ followed by hypertension which was $14 \%$. Our study emphasizes the need to focus on noncommunicable diseases and cervical cancer screening, especially in a vulnerable population like the FSW. Since cervical cancer is one of the preventable cancers, awareness needs to be spread regarding cervical cancer screening and vaccination against HPV.

\section{ACKNOWLEDGEMENTS}

This study was undertaken with the cooperation of a Non-Government Organisation 'Newlight' known for providing night shelter and education for the children of sex-workers for over two decades in the same area.

\section{DECLARATIONS}

Funding: Martinian '78 for arranging the health-camp and medicine.

\section{Conflict of interest: None}

\section{REFERENCES}

1. Bhattacharya I. Vulnerability Of Children Living In The Red Light Areas Of Kolkata, India. SANLAAP; 2010.

2. National AIDS Control Organization \& ICMRNational Institute of Medical Statistics (2018). HIV Estimations 2017: Technical Report. New Delhi: NACO, Ministry of Health and Family Welfare, Government of India.

3. Annual report 2015-2016 NACO. Available from: http://naco.gov.in/sites/default/files/Annual\%20Re port\%202015-16.pdf (accessed on 4 April, 2021)

4. Paul R, Suresh M, Mondal J. Factors influencing health-care access of female commercial sex workers in India: an in-depth review. Int $\mathrm{J}$ Community Med Public Health. 2017;4:886-90.

5. Das M, Nanda P, Sarin E, Narang A. Universal Access for Women and Girls: Accelerating Access to HIV Prevention, Treatment, Care and Support for Female Sex Workers and Wives of Migrant Men. New Delhi: ICRW and UNDP; 2012. Available from: http://strive.1shtm.ac.uk/system/files/attach

6. Deb S. Experience of CSWs with HIV/AIDS: An exploratory study in Kolkata, India. Presented at the XVI International AIDS Conference, Toronto, Canada; 2006. [Abstract no. CDD1300].

7. King EJ, Maman S, Bowling JM, Moracco KE, Dudina V. The Influence of Stigma and Discrimination on Female Sex Workers' Access to HIV Services in St. Petersburg, Russia. AIDS Behav. 2013;17:2597-603.

8. Ministry of Health and Family Welfare. National Family Health Survey -4. International Institute of Population Sciences; p. State Fact Sheet West Bengal. Available at https://ruralindiaonline.org/en/library/resource/nati 
onal-mental-health-survey-of-india-2015-16-

summary/ (accessed on 4 April, 2021)

9. Webb P, Stordalen GA, Singh S, Wijesinha-Bettoni R, Shetty P, Lartey A. Hunger and malnutrition in the 21 st century. bmj. 2018 Jun 13;361.

10. Healthy diet [Internet]. Who.int. 2019 [cited 30 December 2019]. Available from: https://www.who.int/en/news-room/factsheets/detail/healthy-diet

11. Tandon BN, Acharya SK, Tandon A. Epidemiology of hepatitis B virus infection in India. Gut. 1996;38 Suppl 2(Suppl 2):S56-9. doi: 10.1136/gut.38.suppl_2.s56. PMID: 8786056; PMCID: PMC1398036.

12. Desai VK, Kosambiya JK, Thakor HG, Umrigar DD, Khandwala BR, Bhuyan KK. Prevalence of sexually transmitted infections and performance of STI syndromes against aetiological diagnosis, in female sex workers of red light area in Surat, India. Sex Transm Infect. 2003;79:111-5

13. Bristow CC, Brown B, Marg L, Iñiguez RI, Meckel-Parker K, Silverman JG, Magis-Rodriguez C, Gaines TL, Brouwer KC. Prevalence and correlates of cervical abnormalities among female sex workers in Tijuana, Mexico. Int J STD AIDS. 2019 Aug;30(9):861-867. doi: 10.1177/0956462419841464. Epub 2019 Jun 3. PMID: 31159713; PMCID: PMC6901098.
14. Richards SD, Stonbraker S, Halpern M, Amesty S. Cervical cancer screening among transactional female sex workers in the Dominican Republic. International journal of STD \& AIDS. 2018 Oct;29(12):1204-14.

15. Mondal SK, Basak B, Roy DN, Mandal PK, Sinha S. Evaluation of vaginal cytology in female sexworkers: A study in a tertiary hospital of eastern India. J Cytol [Internet]. 2014 [cited 2018 Sep 7]: 31 (1): 7-10.

16. Bhatnagar K, Baghel K. Epidemiology of patients with bad cervix attending gynaecology OPD of a tertiary care centre in Western Uttar Pradesh, India. International Journal of Reproduction, Contraception, Obstetrics and Gynecology, 2017; 6(3), 791-796. doi:http://dx.doi.org/10.18203/23201770.ijrcog20170471

17. Misra JS, Srivastava AN, Gupta HP. Results of Cervical Cancer Screening in the Rural Population of Lucknow West, India, through a Camp Approach. Acta Cytol. 2018;62(4):273-278. doi: 10.1159/000489078. Epub 2018 Jun 13. PMID: 29898440.

18. Yasmeen J, Qurieshi MA, Manzoor NA, Asiya W, Ahmad SZ. Community-based screening of cervical cancer in a low prevalence area of India: a cross sectional study. Asian Pac J Cancer Prev. 2010 Jan 1;11(1):231-4. 